\title{
A Welfare Decomposition in Quasi-Linear Economies*
}

\author{
Taiji Furusawa $^{\dagger} \quad$ Hideo Konishi ${ }^{\ddagger}$
}

August 27, 2003

\begin{abstract}
We propose a decomposition of social welfare when consumers have quasi-linear utility functions under certain conditions satisfied in many models of imperfect competition. In our decomposition, social welfare is expressed as the sum of consumers' gross utilities and trade surplus of non-numeraire commodities, which contribute to consumers' utilities non-linearly. This decomposition is useful especially when we assess the impact of trade liberalization on individual countries.
\end{abstract}

\section{JEL Classification Number: F10}

Keywords: social welfare, quasi-linear utility, GATT think

*Furusawa gratefully acknowledges financial supports from the Japan Economic Research Foundation. Konishi gratefully acknowledges financial supports from the Japan Society for Promotion of Science research.

${ }^{\dagger}$ Faculty of Economics, Hitotsubashi University, 2-1 Naka, Kunitachi, Tokyo 186-8601 Japan. (e-mail) furusawa@econ.hit-u.ac.jp

${ }_{\ddagger}^{\ddagger}$ Department of Economics, Boston College, Chestnut Hill, MA 02467, USA. (e-mail) hideo.konishi@bc.edu 


\section{Introduction}

In economic analyses, quasi-linear utility functions are often used to describe consumers' preferences. When consumers' preferences are represented by quasi-linear utility functions, every consumer's marginal utility of income always equals unity as long as she consumes a positive amount of the numeraire good, which linearly contributes to her utility. Owing to this feature, social welfare of a country or a region can be represented by the economy's total surplus, which is the sum of consumer surplus, producer surplus, and government surplus (such as tariff revenue), and hence we can proceed with a partial equilibrium analysis regarding non-numeraire commodities, which contribute to consumers' utilities non-linearly. In this paper, we propose another decomposition of social welfare: when consumers' preferences are described by quasi-linear utility functions, and all countries share the same constant-returnsto-scale production technology for each commodity that they produce, social welfare can be expressed as the sum of consumers' gross utilities and trade surplus of non-numeraire commodities. ${ }^{1}$

This decomposition may appear rather odd, since it might look supporting mercantilism. Krugman (1991, pp. 24-25) points out that participants of international trade negotiations seem to follow a set of principles, which he calls "GATT-think": '(1) Exports are good. (2) Imports are bad. (3) Other things equal, an equal increase in imports and exports is good.' He states that GATT-think is nonsense to an economist. Although we agree that it is indeed nonsense as it is, our decomposition gives some economic interpretation of GATTthink, and clarifies what are true and untrue about it. According to our decomposition, an increase in trade surplus of non-numeraire commodities is good given that a cause of such an increase does not decrease consumers' gross utilities. Notice that an increase in

\footnotetext{
${ }^{1}$ The second condition may look strong. In many models with differentiated commodities under imperfect competition, however, each firm chooses to produce a different variety of the good from other firms'. In such cases, the assumption that all countries share the same technology for each commodity is automatically satisfied since there is only one firm in the world which produces each commodity. Our second condition is also satisfied under perfect competition with the so-called Armington assumption, i.e., goods are differentiated by the country of production, which is commonly adopted in numerical analyses, since under the Armington assumption no two countries produce an identical good.
} 
imports raises consumers' gross utilities in general, as well as it lowers trade surplus; so our decomposition would not support mercantilism. ${ }^{2}$

Our decomposition of social welfare is useful especially when we assess the impact of trade liberalization, whether multilateral or preferential. Consider, for example, trade liberalization of some importable non-numeraire goods. Trade liberalization is likely to increase consumers' gross utilities. Then our decomposition suggests that trade liberalization enhances social welfare if trade surplus of non-numeraire commodities does not deteriorate too much. Bagwell and Staiger (1999) show that reciprocity, which is one of the most important GATT principles, facilitates mutual trade liberalization between two large countries. They define reciprocity as mutual changes in trade policies that induce equal changes in countries' individual import volumes. That is, under reciprocity, mutual trade liberalization does not change each country's trade surplus with the other. Since mutual trade liberalization is likely to raise consumers' gross utilities, it is easy to see with our decomposition that social welfare of each country is likely to rise. Furusawa and Konishi (2003) use our welfare decomposition and show that reciprocal trade liberalization between two symmetric countries does not change each country's trade surplus with its partner country but increases its trade surplus with third countries when goods are substitutable from one another. Then we can immediately conclude with our decomposition that even in the case where there are more than two countries, bilateral trade liberalization is likely to enhance social welfare of the two countries.

\section{The Model and Results}

Let $N$ denote a finite set of countries and $K$ denote a finite set of non-numeraire commodities. A subset of $K$ may be the set of varieties (or commodities) of a good in an imperfectly

\footnotetext{
${ }^{2}$ Our decomposition does not also contradict to the traditional decomposition of gains from trade into the terms-of-trade effect and volume-of-trade effect. An improvement of the terms of trade is directly reflected in a favorable change in trade surplus in our decomposition with volumes of exports and imports being kept constant at original levels before the change in the terms of trade. See Harrison, Rutherford, and Wooton (1993) and Kowalczyk (2000) for such welfare decompositions in the analyses of customs unions.
} 
competitive industry, while another element of $K$ may represent a competitively produced good. There are $|K|+1$ commodities in the economy, including the numeraire good 0 . We consider the situation in which every consumer's preferences are represented by a quasi-linear utility function. To simplify the exposition, we suppose that there is only one consumer in every country, or equivalently there is a quasi-linear social welfare function for every country. The following analysis remains valid even in the case where every country is populated by many consumers with different tastes as long as every consumer's preferences are represented by a quasi-linear utility function and a country's well-being is measured by a utilitarian social welfare function, i.e., the sum of all consumers' utilities. Let $\left(q_{0}^{i}, q^{i}\right) \in \Re_{+} \times \Re_{+}^{|K|}$ denote the consumption vector of country $i$. Then country $i$ 's social welfare function is written as

$$
U^{i}\left(q_{0}^{i}, q^{i}\right)=u^{i}(q)+q_{0},
$$

where $u^{i}(q)$ is a monotonically increasing, concave function.

Country $i$ is endowed with $I_{i}$ units of the numeraire good, from which non-numeraire commodities are produced. ${ }^{3}$ We assume that $I_{i}$ is sufficiently large so that some amount of the numeraire good is left for consumption in each country. We start with general cost functions, and then we impose conditions in order to get our main decomposition result. Country $i$ 's cost function of producing commodity $k$ is described by $C_{i k}$ such that $C_{i k}\left(y_{i k}\right)$ units of the numeraire good are required to produce $y_{i k}$ units of good $k$ in country $i .^{4}$

Countries impose tariffs on their imports from other countries. Let $t_{j k}^{i}$ denote the rate of specific tariff that country $i$ imposes on good $k$ imported from country $j$. We allow the situations in which countries select different tariff rates on the same good depending on the production location. That is, our analysis can be applied to the case where some groups of countries have signed preferential trade agreements such as customs unions and free trade

\footnotetext{
${ }^{3}$ Alternatively, we can consider an economy in which each country is endowed with production factors, such as labor and capital, and every good is produced from those factors, with the numeraire good produced by a constant-returns-to-scale technology. It is easy to see that these two specifications correspond to the same economic environment.

${ }^{4}$ For each variable representing production or consumption of good $k$, we use a subscript to specify the production location and a superscript to represent the consumption location.
} 


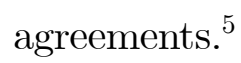

Let $p_{k}^{i}$ denote the consumer price for good $k$ in country $i$. The price of the numeraire good is normalized to unity. Also let $x_{i k}^{j}$ denote country $i$ 's supply of good $k$ to country $j$ ( $x_{i k}^{i}$ is the amount of domestic consumption in country $i$ ). Then we have the following relations between productions and supplies and between consumptions and supplies.

$$
y_{i k}=\sum_{j \in N} x_{i k}^{j}, \quad \text { and } q_{k}^{i}=\sum_{j \in N} x_{j k}^{i} .
$$

Now, country $i$ 's budget constraint can be written as

$$
\underbrace{\sum_{k \in K} p_{k}^{i} q_{k}^{i}+q_{0}^{i}}_{\text {expenditure }}=I_{i}+\underbrace{\sum_{k \in K} \sum_{j \in N}\left(p_{k}^{j}-t_{i k}^{j}\right) x_{i k}^{j}-\sum_{k \in K} C_{i k}\left(y_{i k}\right)}_{\text {producer surplus }}+\underbrace{\sum_{k \in K} \sum_{j \in N} t_{j k}^{i} x_{j k}^{i}}_{\text {tariff revenue }} .
$$

Solving this equation for $q_{0}^{i}$ and substituting the resulting expression into (1), we obtain

$$
\begin{aligned}
U^{i}\left(q_{0}^{i}, q^{i}\right)= & u^{i}\left(q^{i}\right)-\sum_{k \in K} p_{k}^{i} q_{k}^{i} \\
& +\sum_{k \in K} \sum_{j \in N}\left(p_{k}^{j}-t_{i k}^{j}\right) x_{i k}^{j}-\sum_{k \in K} C_{i k}\left(y_{i k}\right) \\
& +\sum_{k \in K} \sum_{j \in N} t_{j k}^{i} x_{j k}^{i}+I_{i} .
\end{aligned}
$$

The terms in the first line of the right-hand side of (2) represent the consumer surplus from the consumption of non-numeraire commodities. The terms in the second line show the producer surplus. The first term in the third line represents the government surplus, which is nothing but the tariff revenue in the current setting, and the second term is just a constant signifying the endowment of the numeraire good. Since we can effectively ignore any constant terms in utility functions, we have confirmed a well-known result that social welfare is measured by total surplus when the underlying utility functions are quasi-linear.

Now, we can obtain a welfare decomposition with general cost functions by rewriting (2).

\footnotetext{
${ }^{5}$ We can also include taxes and subsidies on domestic production and consumption without affecting our main results.
} 
We use $q_{k}^{i}=\sum_{j \in N} x_{j k}^{i}$ in the transformation.

$$
\begin{aligned}
& U^{i}\left(q_{0}^{i}, q^{i}\right) \\
& =u^{i}\left(q^{i}\right)-\sum_{k \in K} \sum_{j \in N} p_{k}^{i} x_{j k}^{i}+\sum_{k \in K} \sum_{j \in N}\left(p_{k}^{j}-t_{i k}^{j}\right) x_{i k}^{j}+\sum_{k \in K} \sum_{j \in N} t_{j k}^{i} x_{j k}^{i}-\sum_{k \in K} C_{i k}\left(y_{i k}\right)+I_{i} \\
& =u^{i}\left(q^{i}\right)+\sum_{j \in N \backslash\{i\}} \sum_{k \in K}\left(p_{k}^{j}-t_{i k}^{j}\right) x_{i k}^{j}-\sum_{j \in N \backslash\{i\}} \sum_{k \in K}\left(p_{k}^{i}-t_{j k}^{i}\right) x_{j k}^{i}-\sum_{k \in K} C_{i k}\left(y_{i k}\right)+I_{i} .
\end{aligned}
$$

The first term on the right-hand of the last equation shows consumers' gross utilities that are derived from the consumption of non-numeraire commodities. The second and third terms represent country $i$ 's export values and import values, respectively. Thus, they together show country $i$ 's trade surplus of non-numeraire commodities. There are two things to note on this decomposition (3). First, trade surplus in the decomposition is the one that only takes into account of the non-numeraire commodities. It does not include trade value of the numeraire good, so that trade surplus in the decomposition is different from the "actual" trade surplus of country $i .{ }^{6}$ Second, although it may appear that "exports are good" and "imports are bad" in our decomposition, neither statement is unambiguously true since exports also affect production costs and imports affect the level of consumers' gross utilities.

The welfare decomposition (3) becomes more useful if all countries share the same constant-returns-to-scale production technology for each commodity that they produce. In such cases, the cost function for good $k$ can be written as

$$
C_{i k}\left(y_{i k}\right)=c_{k} y_{i k}
$$

Then, it follows from $y_{i k}=\sum_{j \in N} x_{i k}^{j}$ that

$$
\begin{aligned}
\sum_{k \in K} C_{i k}\left(y_{i k}\right) & =\sum_{k \in K} c_{k} \sum_{j \in N} x_{i k}^{j} \\
& =\sum_{k \in K} c_{k} x_{i k}^{i}+\sum_{j \in N \backslash\{i\}} \sum_{k \in K} c_{k} x_{i k}^{j} \\
& =\sum_{k \in K} c_{k} \sum_{j \in N} x_{j k}^{i}-\sum_{j \in N \backslash\{i\}} \sum_{k \in K} c_{k} x_{j k}^{i}+\sum_{j \in N \backslash\{i\}} \sum_{k \in K} c_{k} x_{i k}^{j} .
\end{aligned}
$$

\footnotetext{
${ }^{6}$ Indeed, "actual" trade surplus always equals zero in simple trade models that do not consider international borrowing and lending.
} 
Substituting $q_{k}^{i}=\sum_{j \in N} x_{j k}^{i}$ into (4) and the resulting equation into (3), we obtain

$$
\begin{aligned}
U^{i}\left(q_{0}^{i}, q^{i}\right)= & u^{i}\left(q^{i}\right)-\sum_{k \in K} c_{k} q_{k}^{i} \\
& +\sum_{j \in N \backslash\{i\}} \sum_{k \in K}\left(p_{k}^{j}-c_{k}-t_{i k}^{j}\right) x_{i k}^{j}-\sum_{j \in N \backslash\{i\}} \sum_{k \in K}\left(p_{k}^{i}-c_{k}-t_{j k}^{i}\right) x_{j k}^{i}+I_{i} .
\end{aligned}
$$

Now, let us define the subutility function $\tilde{u}^{i}$ by

$$
\tilde{u}^{i}\left(q^{i}\right)=u^{i}\left(q^{i}\right)-\sum_{k \in K} c_{k} q_{k}^{i}
$$

and the corresponding utility function $\tilde{U}^{i}$ by $\tilde{U}^{i}\left(q_{0}^{i}, q^{i}\right)=\tilde{u}^{i}\left(q^{i}\right)+q_{0}^{i}$. This normalization of the utility function shifts down the demand curve for good $k$ by the amount of the unit cost $c_{k}$ as the partial derivative of $\tilde{u}^{i}$ in (6) with respect to $q_{k}^{i}$ indicates. It is well known that in such a case, the original model and the normalized model yield the same equilibrium production and consumption levels, with the price for good $k$ in the normalized model equal to $\tilde{p}_{k}^{i}=p_{k}^{i}-c_{k}$. With this normalization, (5) can be rewritten as

$$
\tilde{U}^{i}\left(q_{0}^{i}, q^{i}\right)=\tilde{u}^{i}\left(q^{i}\right)+\sum_{j \in N \backslash\{i\}} \sum_{k \in K}\left(\tilde{p}_{k}^{j}-t_{i k}^{j}\right) x_{i k}^{j}-\sum_{j \in N \backslash\{i\}} \sum_{k \in K}\left(\tilde{p}_{k}^{i}-t_{j k}^{i}\right) x_{j k}^{i}+I_{i} .
$$

Proposition 1 If all countries share the same constant-returns-to-scale production technology for each commodity that they produce, we can normalize utility functions such that the demand curve for each good shifts down by the unit costs of production. In such cases, social welfare of each country can be measured by the sum of consumers' gross utilities (derived from the consumption of non-numeraire commodities) and trade surplus of non-numeraire commodities. 


\section{References}

[1] Bagwell, Kyle and Robert W. Staiger, 1999, "An Economic Theory of GATT," American Economic Review 89, 215-248.

[2] Furusawa, Taiji and Hideo Konishi, 2003, "Free Trade Networks," unpublished manuscript.

[3] Harrison, Glenn W., Thomas F. Rutherford, and Ian Wooton, 1993, "An Alternative Welfare Decomposition for Customs Unions," Canadian Journal of Economics 26, 961968.

[4] Kowalczyk, Carsten, 2000, "Welfare and Integration," International Economic Review 41, 483-494.

[5] Krugman, Paul, 1991, "The Move Toward Free Trade Zones," in Policy Implications of Trade and Currency Zones: A Symposium Sponsored by the Federal Reserve Bank of Kansas City, Federal Reserve Bank of Kansas City, 7-41. 